\title{
Facile Synthesis of Trisaccharide Moiety Corresponding to Antitumor Activity in Triterpenoid Saponins Isolated from Pullsatilla Roots
}

\author{
Seong-Cheol Bang, Hyun-Hee Seo, Hwi-Yeol Yun, and Sang-Hun Jung* \\ College of Pharmacy, Chungnam National University; Daejon 305-764, Korea. \\ Received February 7, 2007; accepted August 29, 2007
}

\begin{abstract}
A trisaccharide found in triterpenoid saponins isolated from Pullsatilla roots appears as an important promoiety for the enhancement of anticancer activity of their aglycones. Thus a facile synthetic method for a trisaccharide moiety, allyl-2,3,4-tri- $O$-benzoyl- $\alpha$-L-rhamnopyranosyl-(1 $\rightarrow 2)$-[2,3,4,6-tetra- $O$-benzoyl- $\beta$-D-glucopyranosyl-( $1 \rightarrow 4)]-3-O$-benzoyl- $\beta$-L-arabinopyranoside $(3)$, has been firstly developed through the regio- and stereoselective glycosylations from arabinose in total $16 \%$ yield via route 2 (eight steps). In this synthetic procedure, the protection of anomeric -OH of L-arabinose with equatorially oriented allyl group unlike with the axial 4-methoxybenzyl protecting group well promoted glycosyl bond formation between $\alpha$-L-rhamnopyranosyl trichloroacetimidate and 2-OH of arabinose. As expected, the synthesized trisaccharide moiety 3 has no cytotoxicity $\left(\mathrm{ED}_{50}:>100 \mu \mathrm{M}\right)$ against three human cancer cell lines (A-549, SK-OV-3, and SK-MEL-2), respectively.
\end{abstract}

Key words trisaccharide; Pullsatilla roots; regio- and stereoselective glycosylation

Saponins, the glycosides of steroids or triterpenes, are widely distributed in plants and animals. ${ }^{1)}$ They exist in relatively high quantities in many significant food and beverage plants, including oats, peanuts, soybeans, lentils, mung beans, garlic, onions, spinach, asparagus, jujube, quillaja and tea. Saponins also are generally found as active constituents in many well known oriental herbal medicines such as ginseng, notoginseng, licorice, horse chestnut, red clover, senegae, and primula. ${ }^{2)}$ Many previous studies reveal that saponins show various physiological and pharmacological activities, such as anti-cancer, anti-inflammatory, cardiovascular, and cytotoxic activities. ${ }^{3,4)}$ The oligosaccharides integrated into the saponins have a very important role in their bioactivity and thus the interest in this sugar unit is rapidly increasing. For example, when the ether-linked tetrasaccharide was removed from julibrosides, its cytotoxicity dramatically decreased. We recently reported Pulsatilla saponin $\mathrm{D}$, hederagenin 3- $O$ - $\alpha$-L-rhamnopyranosyl-( $(1 \rightarrow 2)$-[ $\beta$-D-glucopyranosyl-( $(1 \rightarrow 4)]-\alpha$-L-arabinopyranoside, as an anticancer component. ${ }^{5)}$ In addition, a total 17 triterpenoid saponins including six new saponins were isolated from Pullsatilla kore- ana $\mathrm{N}$. root and the structure-activity relationships of antitumoral saponins was published. ${ }^{6,7)}$ Among them, Pullsatilla saponin D (1, inhibition ratio (IR): $66.9 \%$ against LLC lung carcinoma xengraft model at $6.0 \mathrm{mg} / \mathrm{kg} / \mathrm{d}$ i.p., $\mathrm{ED}_{50} 3.04$ $13.17 \mu \mathrm{M})$ and oleanolic acid 3-O- $\alpha$-L-rhamnopyranosyl$(1 \rightarrow 2)$-[ $\beta$-D-glucopyranosyl-( $(1 \rightarrow 4)]-\alpha$-L-arabinopyranoside $\left(2, \mathrm{ED}_{50} 1.57-8.36 \mu \mathrm{M}\right)$ exhibited highly potent anticancer activity. Pulsatilla saponin D shows five times more active in anticancer test than its aglycone $\left(\mathrm{ED}_{50} ;>50 \mathrm{~mm}\right) .{ }^{8,9)}$ This indicated that the presence of a sugar moiety, $O-\alpha$-Lrhamnopyranosyl-( $1 \rightarrow 2)$-[ $\beta$-D-glucopyranosyl- $(1 \rightarrow 4)]-\alpha$-Larabinopyranoside, at $\mathrm{C}-3$ position enhances the activity. It has been postulated that the linked trisaccharide improves the bioavailability in tumor tissue in vivo. Therefore, this moiety could be utilized as a promoiety for the increment of the activity of other antitumoral compounds and their solubility in water as shown in Fig. 1. Indeed, glucose has been integrated into anticancer agents as a conjugate for the improvement of their activity since cancer cells have increased rate of glucose metabolism compared with healthy cells and over-expression of GLUT-1. ${ }^{10,11)}$ This approach has been also applied to pep-
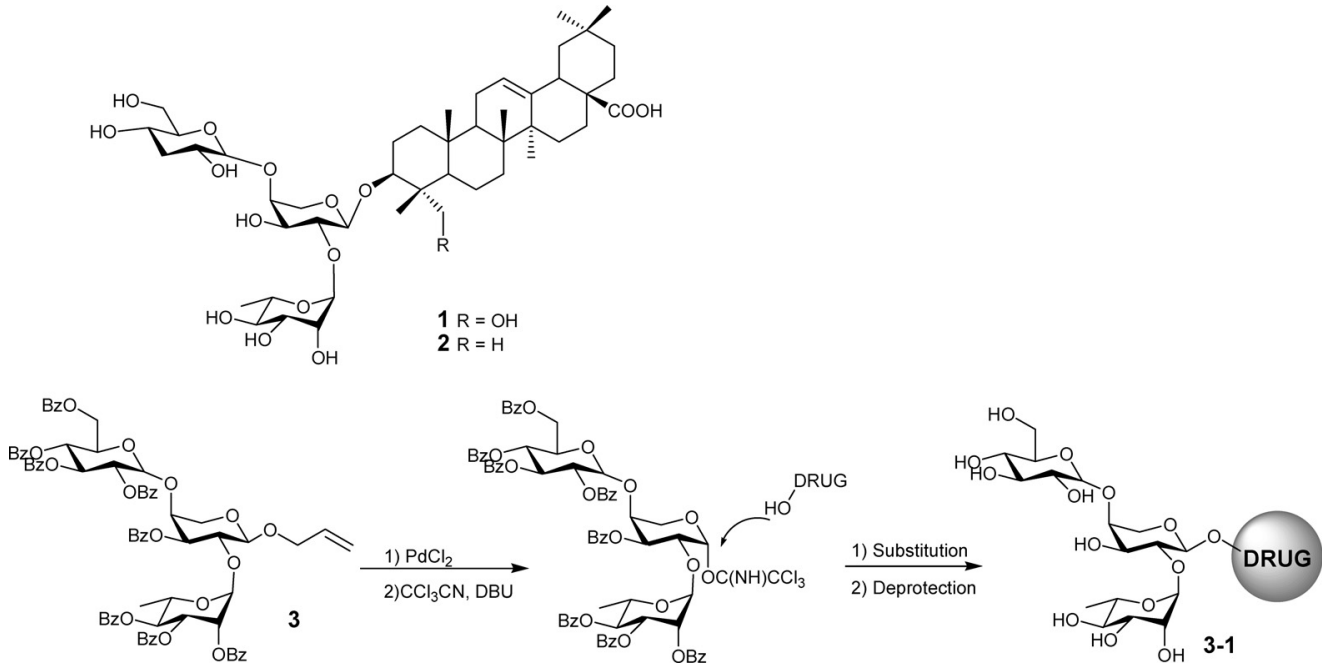

Fig. 1. Structures of Pullsatilla Saponin 1 and 2, Target Trisaccharide Template 3, and a Proposing Example (3-1) Conjugated with Drug 
tide drugs ${ }^{12)}$ and cytotoxic agents ${ }^{13,14)}$ for improvement of delivery into the central nervous system (CNS). Although there are some studies on natural oligosaccharide (i.e., Digitoxin) ${ }^{15)}$ these attempts have been mainly restricted to conjugation with a monosaccharide. ${ }^{16)}$ For the concrete investigation of pharmacological function as a promoiety of $\alpha$-Lrhamnopyranosyl-( $1 \rightarrow 2)$-[ $\beta$-D-glucopyranosyl- $(1 \rightarrow 4)]-\alpha$-Larabinopyranosyl moiety of $\mathbf{1}$, the simple and effective synthetic route of this sugar moiety is urgently needed. Accordingly, a synthetic method of trisaccharide moiety (3) was designed and the detail procedure is described in this paper.

\section{Results and Discussion}

Although numerous efforts have been devoted to the synthesis of diverse carbohydrate structures which is occurred in nature, it is still complicated in their synthesis. This can be attributed mainly to difficulties in synthesizing oligosaccharides, unlike proteins and nucleic acids, because (i) the molecules are typically branched rather than linear, (ii) the monosaccharide units can be connected by $\alpha$ - or $\beta$-linkages, and (iii) oligosaccharide synthesis requires multiple selective protection and deprotection steps. Although considerable progress has been made in the field over the past few decades, there is still no general route for synthesis of oligosaccharide and glycosylation chemistry is often not predictable. ${ }^{17)}$ However the method for the synthesis of oligosaccharides devised by Schmidt and his coworkers are frequently successful for forming mainly or exclusively $\alpha$ - or $\beta$ linkage product. ${ }^{18)}$

Based on this strategy, we efficiently performed the synthesis of protected trisaccharide moiety of $\mathbf{1}$. Initially we selected 4-methoxybenzyl $\alpha$-L-arabinopyranoside (4) as an effective starting point because the synthetic route shown in Chart 1 could be stereoselectively formed $1 \rightarrow 4$ linkage and the 4-methoxybenzyl (MPM) group at anomeric position of $\mathbf{4}$ can be removed under mild condition. The starting compound 4-methoxybenzyl $\alpha$-L-arabinopyranoside (4) synthe- sized readily form L-arabinose in four steps with $40-50 \% .{ }^{19)}$ Reaction of 4-methoxybenzyl $\alpha$-L-arabinopyranoside (4) with 2,2-dimethoxypropane in $N, N$-dimethylformamide (DMF) containing $p$-toluenesulfonic acid ( $p$ - $\mathrm{TsOH})$ at room temperature for $3 \mathrm{~h}$, allylation of 2-OH with allyl bromide and $\mathrm{NaH}$ at $0^{\circ} \mathrm{C}$ for $1 \mathrm{~h}$, and then removal of the acetonide in $70 \%$ aq. acetic acid $(\mathrm{AcOH})$ gave compound 5 in overall $71 \%$ yield (three steps). The 4-methoxybenzyl 2-O-allyl- $\alpha$-Larabinopyranoside (5) was reacted with dibutyltin oxide $\left(\mathrm{Bu}_{2} \mathrm{SnO}\right)$ in $\mathrm{MeOH}$ to give the corresponding 3,4-O-stannylidene derivative, which was subsequently treated with benzyl bromide $(\mathrm{BnBr})$ in the presence of tetrabutylammonium $\left(\mathrm{Bu}_{4} \mathrm{NBr}\right)$ in toluene to afford 4-methoxybenzyl 2-Oallyl-3-O-benzyl- $\alpha$-L-arabinopyranoside 6 in $68 \%$ yield. At first, coupling reaction of $\mathbf{6}$ with thioglucoside donor $7^{20)}$ using $N$-iodosuccinimide (NIS) and triflic acid (TfOH) as an iodonium ion was attempted. ${ }^{21}$ But the desired disaccharide 9 was not produced. Therefore the other coupling condition using trichloroacetimidate donor $\mathbf{8}^{18,22,23)}$ and trimethylsilyl trifluoromethanesulfonate (TMSOTf) as catalyst at $-20^{\circ} \mathrm{C}$ in dry $\mathrm{CH}_{2} \mathrm{Cl}_{2}$ was applied. The completed reaction mixture was purified by silica gel chromatography $(3: 1 \mathrm{cHx}-\mathrm{EtOAc})$ to give the $\beta-(1 \rightarrow 4)$ linked disaccharide 9 (Glc $J_{1,2}$ values $7.6 \mathrm{~Hz})$ as major product $(83 \%)$ contaminated by a small amount of impurities (about 8\%) in NMR spectra. For that reason, an additional purification step using preparative HPLC elution with $80 \%$ acetonitrile (flow rate: $1 \mathrm{ml} / \mathrm{min}$, $t_{\mathrm{R}}=17.53 \mathrm{~min}$ ) was performed to provide pure compound 9 (isolated yield: $71 \%$ ). The $\alpha$-anomer of 9 was not detected. This compound 9 was subsequently treated with palladium chloride $\left(\mathrm{PdCl}_{2}\right)^{24)}$ in $\mathrm{CH}_{2} \mathrm{Cl}_{2}-\mathrm{MeOH}$ to afford 2-O-deallylated disaccharide $\mathbf{1 0}$ in $42 \%$ yield. However, as shown in Chart 1, the final glycosylation reaction of $\mathbf{1 0}$ and trichloroacetimidate $\mathbf{1 1}^{25}$ ) catalyzed by TMSOTf was not accomplished under various conditions. It may be attributed to the instability of 4-methoxybenzyl group at anomeric position of the acceptor under acidic conditions. In recovering
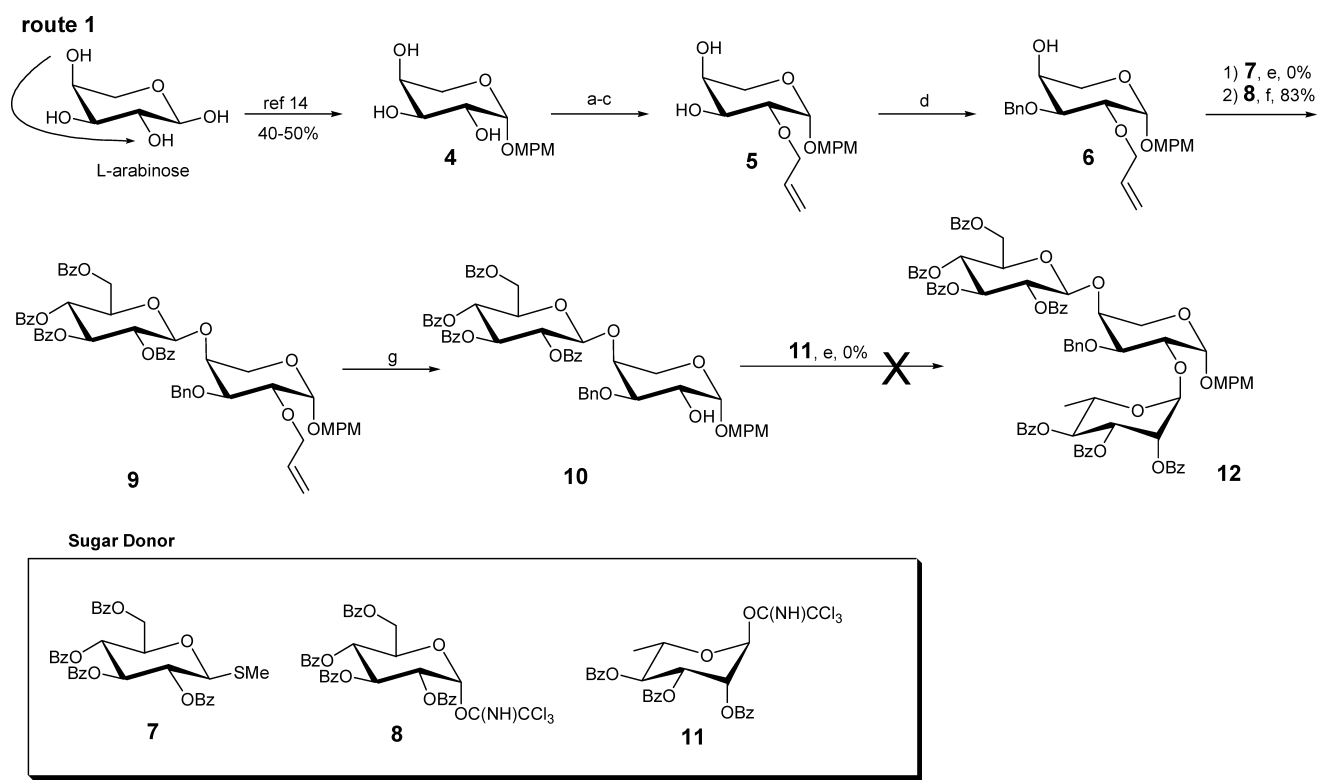

Reagents and conditions: (a) 2,2-dimethoxypropropane, $p$-TsOH, DMF, rt, $6 \mathrm{~h}$; (b) allyl bromide, NaH, DMF, $0{ }^{\circ} \mathrm{C}, 1 \mathrm{~h}$; (c) $70 \%$ aq. $\mathrm{AcOH}, 70{ }^{\circ} \mathrm{C}, 1 \mathrm{~h}, 71 \%$ for three steps; (d) $\mathrm{Bu}_{2} \mathrm{SnO}, \mathrm{MeOH}$, reflux, $3 \mathrm{~h}$; then $\mathrm{BnBr}, \mathrm{Bu}_{4} \mathrm{NBr}, 60^{\circ} \mathrm{C}, 16 \mathrm{~h}, 81 \%$; (e) NIS, TfOH, $4 \AA \mathrm{MS}, \mathrm{CH}_{2} \mathrm{Cl}_{2},-20^{\circ} \mathrm{C}, 1 \mathrm{~h}, 0 \%$; (f) $\mathrm{TMSOTf}, 4 \AA \mathrm{MS}, \mathrm{CH}_{2} \mathrm{Cl} l_{2},-20{ }^{\circ} \mathrm{C}, 2 \mathrm{~h}, 83 \%$ for 9 and $0 \%$ for 12; (g) $\mathrm{PdCl}_{2}, \mathrm{MeOH}, \mathrm{rt}, 48 \mathrm{~h}, 42 \%$.

Chart 1. Attempted Synthesis towards Trisaccharide Template (Route 1) 

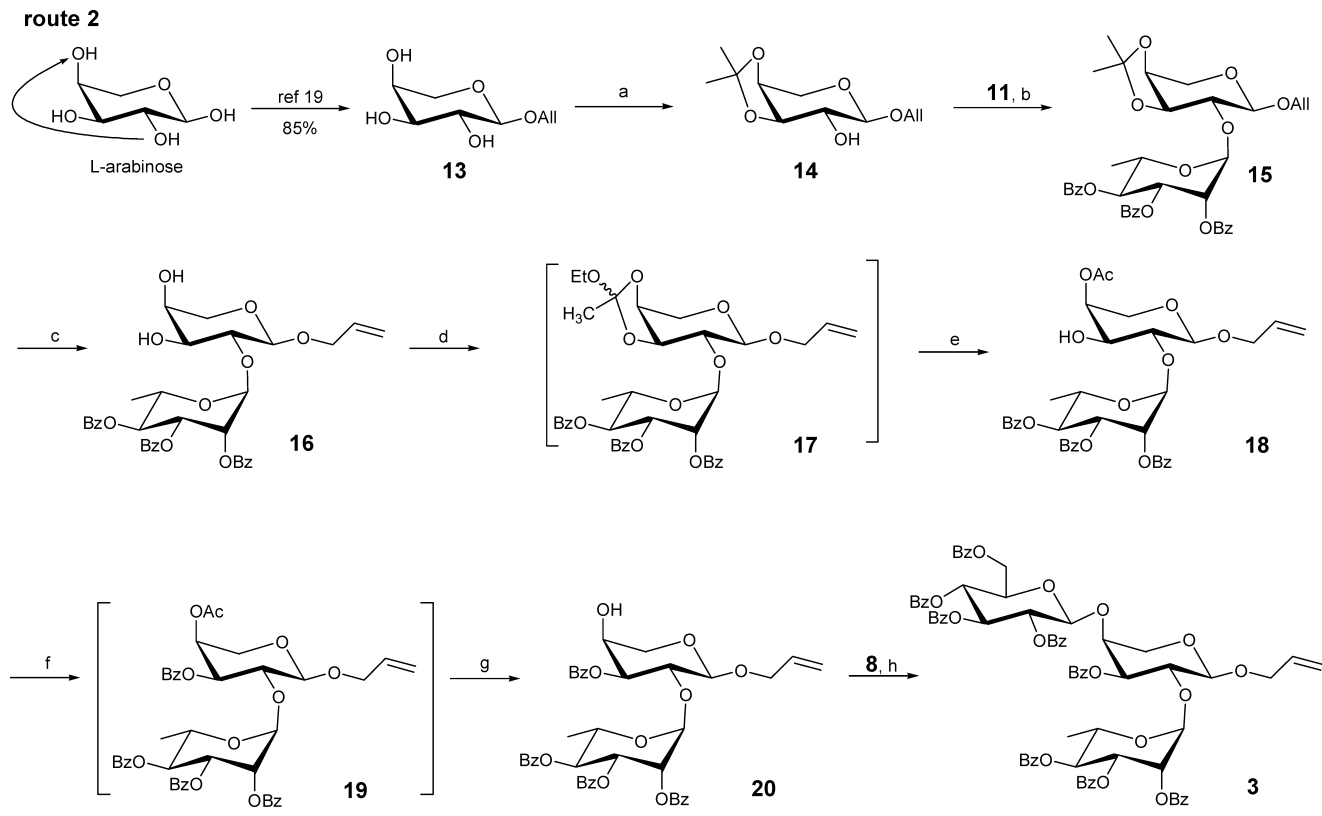

Reagents and conditions: (a) 2,2-dimethoxypropropane, $p$-TsOH, DMF, rt, $6 \mathrm{~h}, 100 \%$; (b) TMSOTf, $4 \AA \mathrm{MS},-20{ }^{\circ} \mathrm{C}, 2 \mathrm{~h}, 63 \%$; (c) $p$-TsOH, $\mathrm{CH}_{2} \mathrm{Cl}_{2} / \mathrm{MeOH} 1: 2$, rt, $2 \mathrm{~h}, 99 \%$; (d) $\mathrm{CH}_{3} \mathrm{C}(\mathrm{OEt})_{3}, p$-TsOH, toluene, rt, $1 \mathrm{~h}$; (e) $80 \%$ aq. $\mathrm{HOAc}, \mathrm{rt}, 1 \mathrm{~h}, 71 \%$ for two steps; (f) BzCl, Pyr, $0{ }^{\circ} \mathrm{C}-\mathrm{rt}, 12 \mathrm{~h}$; (g) $\mathrm{AcCl}, \mathrm{CH}_{2} \mathrm{Cl}_{2} / \mathrm{MeOH} 1: 2,0{ }^{\circ} \mathrm{C}-\mathrm{rt}, 12 \mathrm{~h}, 68 \%$ for two steps; (h) TMSOTf, $4 \AA \mathrm{MS}, \mathrm{CH}_{2} \mathrm{Cl}_{2},-20^{\circ} \mathrm{C}, 2 \mathrm{~h}, 62 \%$.

Chart 2. Completion of the Trisaccharide Template (Route 2)

process of starting material, a by-product lost 4-methoxybenzyl group from 10 was obtained in 11\% yield. Therefore, we needed the revised synthetic route with starting material of Larabinose having more stable and solid protecting group than 4-methoxybenzyl group at anomeric position. Therefore, the more stable and the less crowded allyl group directed equatorially in place of 4-methoxybenzyl group at anomeric position was selected as shown in Chart 2. The starting material compound $\mathbf{1 3}$ having an allyl group at $1-\mathrm{OH}$ was readily prepared in $85 \%$ yield under the Paul's condition. ${ }^{19)}$ Treatment of allyl $\beta$-L-arabinopyranoside (13) with 2,2-dimetoxypropane in dry DMF containing $p$-TsOH at room temperature for $6 \mathrm{~h}$ gave the 3,4-isopropylidene derivative (14), which was used without purification in the next step. Lewis acid-catalyzed assembly of $\mathbf{1 4}$ with the donor 2,3,4-tri- $O$ benzoyl- $\alpha$-L-rhamnopyranosyl tirchloroacetimidate $(\mathbf{1 1})$ by TMSOTf at a low temperature gave disaccharide 15 (63\%) exclusively. The success of the reaction was evident from the down field shift in the ${ }^{1} \mathrm{H}-\mathrm{NMR}$ signal of $\mathrm{H}-2^{\prime}$ in L-arabinose $\left(\delta_{\mathrm{H}} 3.53 \mathrm{ppm}\right.$ in $\mathbf{1 3}$ to $\delta_{\mathrm{H}} 5.88 \mathrm{ppm}$ in $\left.\mathbf{1 5}\right)$ and the chemical shift $5.34(\mathrm{~d}, J=2.0 \mathrm{~Hz}, 1 \mathrm{H})$ of $\mathrm{H}-1^{\prime \prime}$ in rhamnopyranosyl moiety. The following deisopropylidenation with $p$-TsOH in $\mathrm{CH}_{2} \mathrm{Cl}_{2}-\mathrm{MeOH}(1: 2)$ afforded allyl-2,3,4-tri- $O$-benzoyl- $\alpha$-Lrhamnopyranosyl-( $1 \rightarrow 2)$ - $\beta$-L-arabinopyranoside (16) in $99 \%$ yield. For the synthesis of allyl-2,3,4-tri- $O$-benzoyl- $\alpha$-Lrhamnopyranosyl-( $1 \rightarrow 2)-4-O$-acetyl- $\beta$-L-arabinopyranoside (17) monoacetylated on the axial hydroxyl group of arabinose $\mathrm{C}-4$, compound $\mathbf{1 6}$ was treated triethyl orthoacetate $\left(\mathrm{CH}_{3} \mathrm{C}(\mathrm{OEt})_{3}\right)$ and $p$-TsOH as acid catalyst in toluene and subsequently cleaved the intermediate cyclic ortho ester under acidic condition ( $80 \%$ aq. HOAc). As a result, compound $\mathbf{1 8}$ was attained in the good yield (71\%) in two steps. The structure of $\mathbf{1 8}$ was unambiguously confirmed by $400 \mathrm{MHz}{ }^{1} \mathrm{H}-\mathrm{NMR}$ spectroscopy with a singlet peak of acetyl at $\delta 2.17$. Benzoylation of $\mathbf{1 8}$ with benzoyl chloride in pyridine, and then selective 4-O-deacetylation with acetyl chlo- ride in $\mathrm{CH}_{2} \mathrm{Cl}_{2}-\mathrm{MeOH}(1: 2)$ to afford allyl-2,3,4-tri-O-benzoyl- $\alpha$-L-rhamnopyranosyl-( $1 \rightarrow 2)-3-O$-benzoyl- $\beta$-L-arabinopyranoside (20) in $68 \%$ yield in two steps. In the following step, coupling of appropriately protected compound $\mathbf{2 0}$ with 2,3,4,6-tetra- $O$-benzoyl- $\alpha$-D-glucopyranosyl trichloroacetimidate 8 was successfully underwent to give the desired trisaccharide $3(62 \%)$ containing a trace amount of impurities $(<3 \%)$ in NMR spectra. The impurities were readily eliminated by recrystallization from $3: 1$ petroleum ether- $\mathrm{MeOH}$ (isolated yield of 3: 53\%).

Although compound $\mathbf{3}$ is the protected derivative of sugar unit of Pulsatilla saponin D (hederagenin 3-O- $\alpha$-Lrhamnopyranosyl-( $1 \rightarrow 2)$-[ $\beta$-D-glucopyranosyl- $(1 \rightarrow 4)]-\alpha$-Larabinopyranoside), its cytotoxicity was measured against three human cancer cell lines (A-549, SK-OV-3, and SKMEL-2) for the possible prediction of cytotoxic effect of this sugar motif. As expected, this compound did not show any activity $\left(\mathrm{ED}_{50}:>100 \mu \mathrm{M}\right)$. This result might indicate that the trisaccharide moiety of Pulsatilla saponin D would only have the role of carrier moiety of prodrug. Therefore this trisaccharide 3 could be used as a nontoxic promoiety ${ }^{26)}$ for the enhancement of activity of anticancer drugs.

In conclusion, a highly efficient and concise synthesis of trisaccharide moiety $\mathbf{3}$ was developed through the regio- and steroselective glycosylations from arabinose in total $16 \%$ yield via route $\mathbf{2}$ in eight steps. To prepare the full protected and practical trisaccharide moiety allyl-2,3,4-tri- $O$-benzoyl$\alpha$-L-rhamnopyranosyl-( $1 \rightarrow 2)$-[2,3,4,6-tetra- $O$-benzoyl- $\beta$-Dglucopyranosyl- $(1 \rightarrow 4)]$-3- $O$-benzoyl- $\beta$-L-arabinopyranoside (3) closely related with biological activity in Pulsatilla saponins, the protection of anomeric - $\mathrm{OH}$ of L-arabinose with equatorially oriented allyl group unlike with the axial 4methoxybenzyl protecting group well promoted glycosyl bond formation between $\alpha$-L-rhamnopyranosyl trichloroacetimidate and $2-\mathrm{OH}$ of arabinose. The $(1 \rightarrow 4)$ coupling reaction with $\beta$-D-glucopyranose in route 2 gave nearly pure 
product $\mathbf{3}$ and possible benzoyl group transfer products or ortho esters have not been detected. Currently, studies on integrating the synthesized trisaccharide template $\mathbf{3}$ which has a possibility as a targeting soluble carrier of diverse drugs with linkable anticancer agents are underway, and the result will be reported in due course. On the other hand, this result provides a basis of the total synthesis of Pulsatilla saponin D possessing a potent anticancer activity.

\section{Experimental}

All reagents and solvents were dried prior to use according to standard methods (Perrin, D. D.; Amarego, W. L.; Perrin, D. R., Purification of laboratory chemicals; Pergamon: London, 1996). Commercial reagents were used without further purification unless otherwise stated. Reactions were followed by thin-layer chromatography (TLC) on Merck glass silica gel (Kieselgel 60 $\mathrm{F}_{254}$ ) plates that were visualized under a UV lamp. Chromatographic separations were performed on silica gel columns by flash (Kieselgel 40, 0.040 $0.063 \mathrm{~mm}$; Merck) or gravity column (Kieselgel 60, 0.063-0.200 mm; Merck). HPLC was performed using a Shimadzu liquid chromatograph model Class-vp version 6.12, equipped with a SPD-10A UV-vis detector (Shimadzu). The preparative HPLC separation of compound 9 was performed using a Spherisorb ${ }^{\circledR}$ S5 ODS2 column $\left(250 \mathrm{~mm} \times 10 \mathrm{~mm}, \mathrm{RP}^{-\mathrm{C}_{18}}\right.$, $5 \mu \mathrm{m}$, Waters, Milford, MA, U.S.A.), and all solvents for HPLC were filtered through a $0.45 \mu \mathrm{m}$ membrane filter (Waters). Melting points were measured on an Electrothermal melting point apparatus. IR spectra were obtained on $\mathrm{KBr}$ disks using a JASCO Report 100 spectrophotometer. NMR spectra were recorded on Bruker MSL-300 or -500 instrument operating at $400 \mathrm{MHz}$, the chemical shift $(\delta)$ is reported in parts per million downfield from tetramethylsilane (TMS) and from solvent references. Electron impact (EI) mass spectra were obtained on a HP-5988A mass spectrometer, and HR-FAB-MS were recorded on a JMS-HX110/110A spectrometer.

4-Methoxybenzyl 2-O-Allyl- $\alpha$-L-arabinopyranoside (5) Compound 5 was prepared from 4-methoxybenzyl $\alpha$-L-arabinopyranoside $(4,1.5 \mathrm{~g}$, $5.55 \mathrm{mmol}$ ) by following the same procedure described in ref. 8 . The crude product was purified by gradient column chromatography (cyclohexnae $(c \mathrm{Hx}) /$ ethyl acetate (EtOAc), $3: 1 \rightarrow 1: 1)$ to yield pure $5(1.22 \mathrm{~g}, 3.94 \mathrm{mmol}$, $71 \%$ ) as white solid, and the physical, chemical, and spectral NMR data were exactly accorded with the above reference.

4-Methoxybenzyl 2-O-Allyl-3- $O$-benzyl- $\alpha$-L-arabinopyranoside (6) A solution of $5(125 \mathrm{mg}, 0.4 \mathrm{mmol})$ and $\mathrm{Bu}_{2} \mathrm{SnO}(120 \mathrm{mg}, 0.48 \mathrm{mmol})$ in dry $\mathrm{MeOH}(10 \mathrm{ml})$ was refluxed for $3 \mathrm{~h}$ until the solution became clear. Solvents were evaporated under reduced pressure with toluene. The residue was dissolved in dry toluene, benzyl bromide $(120 \mu \mathrm{l}, 1.0 \mathrm{mmol})$ and $\mathrm{Bu}_{4} \mathrm{NBr}$ (156 mg, $0.48 \mathrm{mmol}$ ) were added and the mixture was stirred at $60^{\circ} \mathrm{C}$ for $16 \mathrm{~h}$. Solvents were evaporated and residue was separated by column chromatography using $c \mathrm{Hx}-\mathrm{EtOAc}(3: 1)$ to afford compound 6 (130 mg, $81.2 \%)$ as colorless syrup: $[\alpha]_{\mathrm{D}}^{25}-0.3^{\circ}\left(c=1, \mathrm{CHCl}_{3}\right)$; IR $\left(\mathrm{cm}^{-1}, \mathrm{CH}_{2} \mathrm{Cl}_{2}\right) 3530$ (O-H stretch), 2930 ( $s p^{3}-\mathrm{H}$ stretch), 1715 (conj. $\mathrm{C}=\mathrm{O}$ stretch), $1600(\mathrm{C}=\mathrm{C}$ stretch), 1530 and 1440 (aromatic $\mathrm{C}=\mathrm{C}$ stretch), 1260 and $1100(\mathrm{C}-\mathrm{O}$ stretch); ${ }^{1} \mathrm{H}-\mathrm{NMR}\left(400 \mathrm{MHz}, \mathrm{CDCl}_{3}\right) \delta 7.35-7.24(\mathrm{~m}, 7 \mathrm{H}, \mathrm{Ar}-\mathrm{H}), 6.85(\mathrm{~d}$ $J=8.8 \mathrm{~Hz}, 2 \mathrm{H}, \mathrm{Ar}-\mathrm{H}), 5.88\left(\mathrm{~m}, 1 \mathrm{H},-\mathrm{CH}_{2} \mathrm{CH}=\mathrm{CH}_{2}\right), 5.23(\mathrm{~d}, J=17.2 \mathrm{~Hz}$, $\left.1 \mathrm{H},-\mathrm{CH}_{2} \mathrm{CH}=\mathrm{C}_{2}\right), 5.14\left(\mathrm{~d}, J=10.4 \mathrm{~Hz}, 1 \mathrm{H},-\mathrm{CH}_{2} \mathrm{CH}=\mathrm{C}_{2}\right), 4.81(\mathrm{~d}$, $\left.J=11.6 \mathrm{~Hz}, 1 \mathrm{H},-\mathrm{CH}_{2} \mathrm{MPM}\right), 4.74\left(\mathrm{~d}, J=12.0 \mathrm{~Hz}, 1 \mathrm{H},-\mathrm{CH}_{2} \mathrm{Ph}\right), 4.66(\mathrm{~d}$, $\left.J=11.6 \mathrm{~Hz}, 1 \mathrm{H},-\underline{\mathrm{CH}}_{2} \mathrm{Ph}\right), 4.54\left(\mathrm{~d}, J=11.6 \mathrm{~Hz}, 1 \mathrm{H},-\underline{\mathrm{C}}_{2} \mathrm{MPM}\right), 4.34(\mathrm{~d}$, $\left.J=6.4 \mathrm{~Hz}, 1 \mathrm{H}, \mathrm{H}-1^{\prime}\right), 4.31\left(\mathrm{dd}, J=12.8 \mathrm{~Hz}, J^{\prime}=5.6 \mathrm{~Hz}, 1 \mathrm{H},-\mathrm{CH}_{2} \mathrm{CH}=\mathrm{CH}_{2}\right)$ $4.15\left(\mathrm{dd}, J=12.8 \mathrm{~Hz}, J^{\prime}=5.6 \mathrm{~Hz}, 1 \mathrm{H},-\mathrm{CH}_{2} \mathrm{CH}=\mathrm{CH}_{2}\right), 3.97(\mathrm{dd}, J=10.4 \mathrm{~Hz}$, $\left.J^{\prime}=3.2 \mathrm{~Hz}, 1 \mathrm{H}, \mathrm{H}-5_{\mathrm{a}}^{\prime}\right), 3.89\left(\mathrm{br} \mathrm{s}, 1 \mathrm{H}, \mathrm{H}-4^{\prime}\right), 3.78\left(\mathrm{~s}, 3 \mathrm{H},-\mathrm{OCH}_{3}\right), 3.56(\mathrm{t}$, $\left.J=7.6 \mathrm{~Hz}, 1 \mathrm{H}, \mathrm{H}-3^{\prime}\right), 3.46\left(\mathrm{dd}, J=8.4 \mathrm{~Hz}, J^{\prime}=3.6 \mathrm{~Hz}, 1 \mathrm{H}, \mathrm{H}-5_{\mathrm{b}}^{\prime}\right), 3.38(\mathrm{~d}$. $\left.J=12.4 \mathrm{~Hz}, \quad 1 \mathrm{H}, \quad \mathrm{H}-2^{\prime}\right)$; ESI-MS: $m / z=366\left[\mathrm{M}+\mathrm{Na}^{+}\right.$; HR-FAB-MS: $m / z=366.3831[\mathrm{M}+\mathrm{Na}]^{+}$(Calcd for $\mathrm{C}_{20} \mathrm{H}_{23} \mathrm{O}_{5} \mathrm{Na}, 366.3834$ ).

4-Methoxybenzyl 2,3,4,6-Tetra- $O$-benzoyl- $\beta$-D-glucopyranosyl-( $1 \rightarrow 4)$ 2- $\boldsymbol{O}$-allyl-3- $\boldsymbol{O}$-benzyl- $\boldsymbol{\alpha}$-L-arabinopyranoside (9) A suspension of compound $6(240 \mathrm{mg}, \quad 0.60 \mathrm{mmol})$, trichloroacetimidate $\left.\mathbf{8}^{13,17}\right)(533 \mathrm{mg}$, $0.72 \mathrm{mmol})$, and $4 \AA$ molecular sieves $(500 \mathrm{mg})$ in dry $\mathrm{CH}_{2} \mathrm{Cl}_{2}(20 \mathrm{ml})$ was stirred for $1 \mathrm{~h}$ at room temperature under $\mathrm{N}_{2}$ atmosphere. The mixture was cooled to $-20^{\circ} \mathrm{C}$, then was added TMSOTf $(0.1 \mathrm{eq}, 13 \mu \mathrm{l})$ as catalyst via syringe. After stirring for $2 \mathrm{~h}$ at same temperature, the mixture was neutralized with triethylamine $\left(\mathrm{Et}_{3} \mathrm{~N}\right)$, filtered with Celite, and then concentrated in vacuo. The residue was purified on a $\mathrm{Si}$ gel column chromatography using the $3: 1 \mathrm{cHx}-\mathrm{EtOAc}$ as eluent to give colorless solid 9 (483 $\mathrm{mg}, 82.7 \%)$ contaminated with a little impurity. An additional purification step using preparative HPLC elution with $80 \% \mathrm{MeCN}$ (flow rate: $1 \mathrm{ml} / \mathrm{min}, t_{\mathrm{R}}=17.53 \mathrm{~min}$ ) was performed to give full-purified 9 (405 $\mathrm{mg}$, isolated yield: $71.4 \%)$. But the $\alpha$-anomer of 9 was not detected: $\mathrm{mp} 63-65^{\circ} \mathrm{C} ;[\alpha]_{\mathrm{D}}^{25} 0.03^{\circ}(c=1$, $\left.\mathrm{CHCl}_{3}\right)$; IR $\left(\mathrm{cm}^{-1}, \mathrm{KBr}\right) 2925\left(s p^{3}-\mathrm{H}\right.$ stretch), 1730 (conj. $\mathrm{C}=\mathrm{O}$ stretch), $1600(\mathrm{C}=\mathrm{C}$ stretch), 1520 and 1450 (aromatic $\mathrm{C}=\mathrm{C}$ stretch), 1260 and 1100 (C-O stretch); ${ }^{1} \mathrm{H}-\mathrm{NMR}\left(400 \mathrm{MHz}, \mathrm{CDCl}_{3}\right) \delta 8.02-7.22(\mathrm{~m}, 27 \mathrm{H}, \mathrm{Ar}-\mathrm{H})$ $6.82(\mathrm{~d}, J=8.4 \mathrm{~Hz}, 2 \mathrm{H}, \mathrm{Ar}-\mathrm{H}), 5.90\left(\mathrm{t}, J=9.2 \mathrm{~Hz}, 1 \mathrm{H}, \mathrm{H}-3^{\prime \prime}\right), 5.63(\mathrm{~m}, 2 \mathrm{H}, \mathrm{H}$ $4^{\prime \prime}$ and $\left.-\mathrm{CH}_{2} \mathrm{CH}=\mathrm{CH}_{2}\right), 5.56\left(\mathrm{t}, J=9.1 \mathrm{~Hz}, 1 \mathrm{H}, \mathrm{H}-2^{\prime \prime}\right), 5.13(\mathrm{~d}, J=7.6 \mathrm{~Hz}$, $\left.1 \mathrm{H}, \mathrm{H}-1^{\prime \prime}\right), 5.02\left(\mathrm{~d}, J=18.4 \mathrm{~Hz}, 1 \mathrm{H},-\mathrm{CH}_{2} \mathrm{CH}=\mathrm{CH}_{2}\right), 4.96(\mathrm{~d}, J=10.0 \mathrm{~Hz}$, $\left.1 \mathrm{H},-\mathrm{CH}_{2} \mathrm{CH}=\mathrm{C}_{2}\right), 4.75\left(\mathrm{~d}, J=11.6 \mathrm{~Hz}, 1 \mathrm{H},-\underline{\mathrm{C}}_{2} \mathrm{MPM}\right), 4.61(\mathrm{dd}$ $\left.J=12.4 \mathrm{~Hz}, \quad J^{\prime}=3.6 \mathrm{~Hz}, \quad 1 \mathrm{H}, \quad \mathrm{H}-5^{\prime \prime}\right), 4.52-4.45 \quad\left(\mathrm{~m}, 4 \mathrm{H}, \quad \mathrm{H}-6^{\prime \prime} \quad(2 \mathrm{H})\right.$ $-\mathrm{CH}_{2} \mathrm{MPM}(1 \mathrm{H})$, and $\left.-\underline{\mathrm{CH}}_{2} \mathrm{Ph}(1 \mathrm{H})\right), 4.24\left(\mathrm{~d}, J=6.0 \mathrm{~Hz}, 1 \mathrm{H}, \mathrm{H}-1^{\prime}\right), 4.08-$ $4.04\left(\mathrm{~m}, 2 \mathrm{H},-\mathrm{C}_{2} \mathrm{Ph}\right.$ and $\left.\mathrm{H}-5_{\mathrm{a}}{ }^{\mathrm{a}}\right), 3.94\left(\mathrm{dd}, J=12.8 \mathrm{~Hz}, J^{\prime}=5.6 \mathrm{~Hz}, 1 \mathrm{H}\right.$, $-\mathrm{CH}_{2} \mathrm{CH}=\mathrm{CH}_{2}$ ), $3.90\left(\right.$ br s, $\left.1 \mathrm{H}, \mathrm{H}-4^{\prime}\right), 3.78\left(\mathrm{~s}, 3 \mathrm{H},-\mathrm{OCH}_{3}\right), 3.57$ (dd, $\left.J=12.8 \mathrm{~Hz}, J^{\prime}=5.6 \mathrm{~Hz}, 1 \mathrm{H},-\mathrm{CH}_{2} \mathrm{CH}=\mathrm{CH}_{2}\right), 3.40-3.34\left(\mathrm{~m}, 3 \mathrm{H}, \mathrm{H}-5_{\mathrm{b}}{ }^{\prime}, \mathrm{H}-\right.$ $3^{\prime}$, and H-2'); ESI-MS: $m / z=945\left[\mathrm{M}+\mathrm{Na}^{+}\right.$; HR-FAB-MS: $m / z=944.9480$ $[\mathrm{M}+\mathrm{Na}]^{+}\left(\mathrm{Calcd}\right.$ for $\left.\mathrm{C}_{54} \mathrm{H}_{49} \mathrm{O}_{14} \mathrm{Na}, 944.9482\right)$.

4-Methoxybenzyl $2,3,4,6$-Tetra- $O$-benzoyl- $\beta$-D-glucopyranosyl-(1 $\rightarrow 4)$ 3- $\boldsymbol{O}$-benzyl- $\boldsymbol{\alpha}$-L-arabinopyranoside (10) Palladium chloride $(9 \mathrm{mg}$, $0.05 \mathrm{mmol})$ was added to a solution of compound $9(159 \mathrm{mg}, 0.16 \mathrm{mmol})$ in dry $\mathrm{MeOH}(10 \mathrm{ml})$, and the reaction mixture was stirred for $48 \mathrm{~h}$ at room temperature. After starting material was completely disappeared, the mixture was filtered through Celite, evaporated, and then the residue was purified by column chromatography using the $2: 1 \mathrm{cHx}-\mathrm{EtOAc}$ as eluent to give colorless solid $10(63 \mathrm{mg}, 41.9 \%)$ : $\mathrm{mp} 59-61^{\circ} \mathrm{C}$; $[\alpha]_{\mathrm{D}}^{25} 1.0^{\circ}\left(c=1, \mathrm{CHCl}_{3}\right)$; IR $\left(\mathrm{cm}^{-1}, \mathrm{KBr}\right) 3525(\mathrm{O}-\mathrm{H}$ stretch$), 2920\left(s p^{3}-\mathrm{H}\right.$ stretch), 1730 (conj. $\mathrm{C}=\mathrm{O}$ stretch), 1600 and 1450 (aromatic $\mathrm{C}=\mathrm{C}$ stretch), 1280 and $1100(\mathrm{C}-\mathrm{O}$ stretch); ${ }^{1} \mathrm{H}-\mathrm{NMR}\left(400 \mathrm{MHz}, \mathrm{CDCl}_{3}\right): \delta 8.02-7.23$ (m, 27H, Ar-H), 6.84 $(\mathrm{d}, J=8.4 \mathrm{~Hz}, 2 \mathrm{H}, \mathrm{Ar}-\mathrm{H}), 5.88\left(\mathrm{t}, J=9.6 \mathrm{~Hz}, 1 \mathrm{H}, \mathrm{H}-3^{\prime \prime}\right), 5.65(\mathrm{t}, J=9.6 \mathrm{~Hz}$, $\left.1 \mathrm{H}, \mathrm{H}-4^{\prime \prime}\right), 5.56\left(\mathrm{dd}, J=9.6 \mathrm{~Hz}, J^{\prime}=8.0 \mathrm{~Hz}, 1 \mathrm{H}, \mathrm{H}-2^{\prime \prime}\right), 5.07(\mathrm{~d}, J=7.6 \mathrm{~Hz}$ $\left.1 \mathrm{H}, \mathrm{H}-1^{\prime \prime}\right), 4.78\left(\mathrm{~d}, J=11.2 \mathrm{~Hz}, 1 \mathrm{H},-\mathrm{CH}_{2} \mathrm{MPM}\right), 4.63(\mathrm{dd}, J=12.0 \mathrm{~Hz}$, $\left.J^{\prime}=3.2 \mathrm{~Hz}, 1 \mathrm{H}, \mathrm{H}-5^{\prime \prime}\right), 4.51-4.45\left(\mathrm{~m}, 4 \mathrm{H}, \mathrm{H}-6^{\prime \prime}(2 \mathrm{H}),-\mathrm{CH}_{2} \mathrm{MPM}(1 \mathrm{H})\right.$, and $\left.-\mathrm{CH}_{2} \mathrm{Ph}(1 \mathrm{H})\right), 4.14\left(\mathrm{~d}, J=7.2 \mathrm{~Hz}, 1 \mathrm{H}, \mathrm{H}-1^{\prime}\right), 4.05-4.03\left(\mathrm{~m}, 2 \mathrm{H},-\mathrm{CH}_{2} \mathrm{Ph}\right.$ and $\left.\mathrm{H}-5_{\mathrm{a}}{ }^{\prime}\right), 3.91\left(\mathrm{br} \mathrm{s}, 1 \mathrm{H}, \mathrm{H}-4^{\prime}\right), 3.79\left(\mathrm{~s}, 3 \mathrm{H},-\mathrm{OCH}_{3}\right), 3.48(\mathrm{t}, J=6.8 \mathrm{~Hz}$, $\left.1 \mathrm{H}, \mathrm{H}-3^{\prime}\right), 3.37\left(\mathrm{~d}, J=12.4 \mathrm{~Hz}, 1 \mathrm{H}, \mathrm{H}-2^{\prime}\right), 3.31\left(\mathrm{dd}, J=9.4 \mathrm{~Hz}, J^{\prime}=3.2 \mathrm{~Hz}\right.$, 1H, H-5 ${ }^{\prime}{ }^{\prime}$ ); ESI-MS: $m / z=962[\mathrm{M}+\mathrm{Na}]^{+}$; HR-FAB-MS: $m / z=961.9561$ $[\mathrm{M}+\mathrm{Na}]^{+}$(Calcd for $\left.\mathrm{C}_{54} \mathrm{H}_{50} \mathrm{O}_{15} \mathrm{Na}, 961.9556\right)$.

Allyl-2,3,4-tri- $O$-benzoyl- $\alpha$-L-rhamnopyranosyl-(1 $\rightarrow 2)-3,4-O$-isopropylidene- $\beta$ - $\mathrm{L}$-arabinopyranoside (15) A suspension of $\mathbf{1 3}(300 \mathrm{mg}$, $\left.1.58 \mathrm{mmol}){ }^{12}\right) 2,2$-dimethoxypropane $(388 \mu \mathrm{l}, 3.16 \mathrm{mmol})$, and $p$-TsOH $(30 \mathrm{mg}, 0.16 \mathrm{mmol})$ in dry DMF $(20 \mathrm{ml})$ was stirred for $6 \mathrm{~h}$ at room temperature. The reaction mixture was stopped by the addition of $\mathrm{Et}_{3} \mathrm{~N}(100 \mu \mathrm{l})$ and then the mixture was diluted with diethyl ether $\left(\mathrm{Et}_{2} \mathrm{O}, 100 \mathrm{ml}\right)$ and washed with $\mathrm{H}_{2} \mathrm{O}(100 \mathrm{ml})$. The aqueous layer was extracted with $\mathrm{Et}_{2} \mathrm{O}(100 \mathrm{ml} \times 3)$. The organic layers was combined, washed with satd. $\mathrm{NaHCO}_{3}(400 \mathrm{ml})$ and satd. $\mathrm{NaCl}(400 \mathrm{ml})$, and dried with $\mathrm{Na}_{2} \mathrm{SO}_{4}$. Solvents were evaporated and the residue (allyl- $(1 \rightarrow 2)-3,4-O$-isopropylidene- $\beta$-L-arabinopyranoside, 14) was used without further purification in the following step.

A solution of this isopropylidene $14(278 \mathrm{mg}, 1.21 \mathrm{mmol})$, trichloroacetimidate $11(977 \mathrm{mg}, 1.57 \mathrm{mmol}),{ }^{18)}$ and $4 \AA$ molecular sieves $(500 \mathrm{mg})$ in dry $\mathrm{CH}_{2} \mathrm{Cl}_{2}(20 \mathrm{ml})$ was treated with TMSOTf $(0.1 \mathrm{eq})$ in the same manner as that described for compound 9. After stirring for $2 \mathrm{~h}$ at this temperature, the mixture was neutralized with triethylamine $\left(\mathrm{Et}_{3} \mathrm{~N}\right)$, filtered with Celite, and then concentrated in vacuo. The residue was purified by a Si gel column chromatography using the 5.5:1 $\mathrm{cHx}-\mathrm{EtOAc}$ as eluent to give colorless syrup 15 (434 mg, 63.0\%): $[\alpha]_{\mathrm{D}}^{25} 1.4^{\circ}\left(c=1, \mathrm{CHCl}_{3}\right)$; IR $\left(\mathrm{cm}^{-1}, \mathrm{CH}_{2} \mathrm{Cl}_{2}\right)$ $2920\left(s p^{3}-\mathrm{H}\right.$ stretch), 1730 (conj. $\mathrm{C}=\mathrm{O}$ stretch), $1600(\mathrm{C}=\mathrm{C}$ stretch), 1580 and 1460 (aromatic $\mathrm{C}=\mathrm{C}$ stretch), 1260 and $1120\left(\mathrm{C}-\mathrm{O}\right.$ stretch); ${ }^{1} \mathrm{H}-\mathrm{NMR}$ $\left(400 \mathrm{MHz}, \mathrm{CDCl}_{3}\right) \delta 8.12-7.22(\mathrm{~m}, 15 \mathrm{H}, \mathrm{Ar}-\mathrm{H}), 6.07-5.97(\mathrm{~m}, 1 \mathrm{H}$ $\left.-\mathrm{CH}_{2} \mathrm{CH}=\mathrm{CH}_{2}\right), 5.89\left(\mathrm{dd}, J=10 \mathrm{~Hz}, J^{\prime}=3.6 \mathrm{~Hz}, 1 \mathrm{H}, \mathrm{H}-2^{\prime \prime}\right), 5.81-5.79(\mathrm{~m}$ $\left.1 \mathrm{H}, \mathrm{H}-4^{\prime \prime}\right), 5.64\left(\mathrm{t}, J=9.6 \mathrm{~Hz}, 1 \mathrm{H}, \mathrm{H}-3^{\prime \prime}\right), 5.44\left(\mathrm{dd}, J=17.4 \mathrm{~Hz}, J^{\prime}=1.6 \mathrm{~Hz}\right.$, $\left.1 \mathrm{H},-\mathrm{CH}_{2} \mathrm{CH}=\mathrm{CH}_{2}\right), 5.34\left(\mathrm{~d}, J=2.0 \mathrm{~Hz}, 1 \mathrm{H}, \mathrm{H}-1^{\prime \prime}\right), 5.29(\mathrm{dd}, J=10.4 \mathrm{~Hz}$ $\left.J^{\prime}=1.2 \mathrm{~Hz}, 1 \mathrm{H},-\mathrm{CH}_{2} \mathrm{CH}=\mathrm{CH}_{2}\right), 4.98\left(\mathrm{~d}, J=3.6 \mathrm{~Hz}, 1 \mathrm{H}, \mathrm{H}-1^{\prime}\right), 4.44(\mathrm{dd}$ $\left.J=7.6 \mathrm{~Hz}, J^{\prime}=5.6 \mathrm{~Hz}, 1 \mathrm{H}, \mathrm{H}-5^{\prime \prime}\right), 4.31-4.24\left(\mathrm{~m}, 3 \mathrm{H},-\mathrm{CH}_{2} \mathrm{CH}=\mathrm{CH}_{2}, \mathrm{H}-4^{\prime}\right.$, and $\left.\mathrm{H}-2^{\prime}\right), 4.05\left(\mathrm{dd}, J=13.2 \mathrm{~Hz}, J^{\prime}=6.4 \mathrm{~Hz}, 1 \mathrm{H},-\mathrm{CH}_{2} \mathrm{CH}=\mathrm{CH}_{2}\right), 4.00(\mathrm{~s}$, $\left.2 \mathrm{H}, \mathrm{H}^{\prime} 5^{\prime}\right), 3.87\left(\mathrm{dd}, J=7.8 \mathrm{~Hz}, J^{\prime}=3.6 \mathrm{~Hz}, 1 \mathrm{H}, \mathrm{H}-3^{\prime}\right), 1.55(\mathrm{~s}, 3 \mathrm{H}$, $\left.-\mathrm{O}\left(\mathrm{CH}_{3}\right)_{2} \mathrm{CO}-\right), 1.37$ (s, $\left.3 \mathrm{H},-\mathrm{O}\left(\mathrm{CH}_{3}\right)_{2} \mathrm{CO}-\right), 1.33\left(\mathrm{~d}, J=6.0 \mathrm{~Hz}, 1 \mathrm{H}, \mathrm{H}-6^{\prime \prime}\right)$ ESI-MS: $m / z=712[\mathrm{M}+\mathrm{Na}]^{+}$; HR-FAB-MS: $m / z=711.7066[\mathrm{M}+\mathrm{Na}]^{+}$ (Calcd for $\mathrm{C}_{38} \mathrm{H}_{40} \mathrm{O}_{12} \mathrm{Na}, 711.7068$ )

Allyl-2,3,4-tri- $O$-benzoyl- $\alpha$-L-rhamnopyranosyl- $(1 \rightarrow 2)$ - $\beta$-L-arabinopyranoside (16) $p$-TsOH $(77 \mathrm{mg}, 0.41 \mathrm{mmol})$ was add to a solution of $15(400 \mathrm{mg}, 0.58 \mathrm{mmol})$ in $\mathrm{CH}_{2} \mathrm{Cl}_{2}-\mathrm{MeOH}(1: 2,30 \mathrm{ml})$ and the mixture was stirred at room temperature for $6 \mathrm{~h}$ when the deprotection had completed on TLC $(c \mathrm{Hx}-\mathrm{EtOAc}=3: 1)$, and then $\mathrm{Et}_{3} \mathrm{~N}(0.1 \mathrm{ml})$ was added and the mixture was concentrated and purified by a Si gel column chromatography using the 
3: $1 \mathrm{cHx}$-EtOAc as eluent to give $\mathbf{1 6}(373 \mathrm{mg}, 99.0 \%)$ as a white amorphous solid: $\mathrm{mp} 130-133^{\circ} \mathrm{C} ;[\alpha]_{\mathrm{D}}^{25} 0.9^{\circ}\left(c=1, \mathrm{CHCl}_{3}\right) ; \mathrm{IR}\left(\mathrm{cm}^{-1}, \mathrm{KBr}\right) 3400$ (O-H stretch), 2930 ( $s p^{3}-\mathrm{H}$ stretch), 1720 (conj. $\mathrm{C}=\mathrm{O}$ stretch), $1600(\mathrm{C}=\mathrm{C}$ stretch), 1580 and 1460 (aromatic $\mathrm{C}=\mathrm{C}$ stretch), 1270 and $1120(\mathrm{C}-\mathrm{O}$ stretch); ${ }^{1} \mathrm{H}-\mathrm{NMR}\left(400 \mathrm{MHz}, \mathrm{CDCl}_{3}\right) \delta 8.05-7.23(\mathrm{~m}, 15 \mathrm{H}, \mathrm{Ar}-\mathrm{H}), 6.06$ $5.96\left(\mathrm{~m}, 1 \mathrm{H},-\mathrm{CH}_{2} \mathrm{CH}=\mathrm{CH}_{2}\right), 5.85\left(\mathrm{dd}, J=10 \mathrm{~Hz}, J^{\prime}=3.6 \mathrm{~Hz}, 1 \mathrm{H}, \mathrm{H}-2^{\prime \prime}\right)$, $5.80-5.79\left(\mathrm{~m}, 1 \mathrm{H}, \mathrm{H}-4^{\prime \prime}\right), 5.6\left(\mathrm{t}, J=10.0 \mathrm{~Hz}, 1 \mathrm{H}, \mathrm{H}-3^{\prime \prime}\right), 5.40$ (dd, $\left.J=17.2 \mathrm{~Hz}, J^{\prime}=1.6 \mathrm{~Hz}, 1 \mathrm{H},-\mathrm{CH}_{2} \mathrm{CH}=\mathrm{CH}_{2}\right), 5.25-5.23\left(\mathrm{~m}, 2 \mathrm{H}, \mathrm{H}-1^{\prime \prime}\right.$ and $\left.-\mathrm{CH}_{2} \mathrm{CH}=\mathrm{CH}_{2}\right), 5.10\left(\mathrm{~d}, J=3.6 \mathrm{~Hz}, 1 \mathrm{H}, \mathrm{H}-1^{\prime}\right), 4.43-4.36\left(\mathrm{~m}, 1 \mathrm{H}, \mathrm{H}-5^{\prime \prime}\right)$, $4.29\left(\mathrm{dd}, J=13.0 \mathrm{~Hz}, J^{\prime}=5.0 \mathrm{~Hz}, 1 \mathrm{H},-\mathrm{CH}_{2} \mathrm{CH}=\mathrm{CH}_{2}\right), 4.21(\mathrm{~d}, J=9.2 \mathrm{~Hz}$, $\left.1 \mathrm{H}, \mathrm{H}-4^{\prime}\right), 4.03-3.95\left(\mathrm{~m}, 3 \mathrm{H}, \mathrm{H}-2^{\prime},-\mathrm{CH}_{2} \mathrm{CH}=\mathrm{CH}_{2}\right.$ and $\left.\mathrm{H}-3^{\prime}\right), 3.88(\mathrm{~d}$ $\left.J=12.4 \mathrm{~Hz}, 1 \mathrm{H}, \mathrm{H}-5^{\prime}{ }^{\prime}\right), 3.76\left(\mathrm{dd}, J=12.4 \mathrm{~Hz}, J^{\prime}=1.6 \mathrm{~Hz}, 1 \mathrm{H}, \mathrm{H}-5_{\mathrm{b}}{ }^{\prime}\right), 1.32$ (d, $J=6.4 \mathrm{~Hz}, 1 \mathrm{H}, \mathrm{H}-6^{\prime \prime}$ ); ESI-MS: $m / z=972[\mathrm{M}+\mathrm{Na}]^{+}$; HR-FAB-MS $m / z=671.6423[\mathrm{M}+\mathrm{Na}]^{+}\left(\right.$Calcd for $\left.\mathrm{C}_{35} \mathrm{H}_{36} \mathrm{O}_{12} \mathrm{Na}, 671.6429\right)$.

Allyl-2,3,4-tri- $O$-benzoyl- $\alpha$-L-rhamnopyranosyl- $(1 \rightarrow 2)-4-O$-acetyl- $\beta$ L-arabinopyranoside (18) A solution of $16 \quad(346 \mathrm{mg}, \quad 0.53 \mathrm{mmol})$, $\mathrm{CH}_{3} \mathrm{C}(\mathrm{OEt})_{3}(483 \mu \mathrm{l}, 2.65 \mathrm{mmol})$ and $p$-TsOH $(50 \mathrm{mg}, 0.265 \mathrm{mmol})$ in dry toluene $(10 \mathrm{ml})$ was stirred at room temperature for $2 \mathrm{~h}$. The reaction mixture was neutralized by the addition of $\mathrm{Et}_{3} \mathrm{~N}(300 \mu \mathrm{l})$ at the same temperature. The solvent was removed in vacuo, the residue was dissolved in $\mathrm{CH}_{2} \mathrm{Cl}_{2}(100 \mathrm{ml})$, washed with water $(100 \mathrm{ml} \times 3)$. After drying over $\mathrm{Na}_{2} \mathrm{SO}_{4}$, the extract was concentrated to give cyclic ortho ester intermediate $\mathbf{1 7}$ as a colorless syrup. The crude was then dissolved in $80 \%$ aq. HOAc $(10 \mathrm{ml})$ and stirred at room temperature for $1.5 \mathrm{~h}$. Coevaporation with toluene yielded a colorless syrup, which was then subjected to $\mathrm{Si}$ gel column chromatography using the 2:1 cHx-EtOAc as eluent to give $18(259 \mathrm{mg}, 70.8 \%)$ as a white foam: $\mathrm{mp} 69-71^{\circ} \mathrm{C} ;[\alpha]_{\mathrm{D}}^{25} 1.0^{\circ}\left(c=1, \mathrm{CHCl}_{3}\right)$; IR $\left(\mathrm{cm}^{-1}, \mathrm{KBr}\right) 3450(\mathrm{O}-\mathrm{H}$ stretch), $2950\left(s p^{3}-\mathrm{H}\right.$ stretch), 1730 (conj. $\mathrm{C}=\mathrm{O}$ stretch), $1600(\mathrm{C}=\mathrm{C}$ stretch), 1580 and 1460 (aromatic $\mathrm{C}=\mathrm{C}$ stretch), 1260 and $1120(\mathrm{C}-\mathrm{O}$ stretch); ${ }^{1} \mathrm{H}-\mathrm{NMR}\left(400 \mathrm{MHz}, \mathrm{CDCl}_{3}\right) \delta 8.08-7.24(\mathrm{~m}, 15 \mathrm{H}, \mathrm{Ar}-\mathrm{H}), 6.06$ $5.97\left(\mathrm{~m}, 1 \mathrm{H},-\mathrm{CH}_{2} \mathrm{CH}=\mathrm{CH}_{2}\right), 5.85\left(\mathrm{dd}, J=10.2 \mathrm{~Hz}, J^{\prime}=3.4 \mathrm{~Hz}, 1 \mathrm{H}, \mathrm{H}-2^{\prime \prime}\right)$, $5.77\left(\mathrm{~m}, 1 \mathrm{H}, \mathrm{H}-4^{\prime \prime}\right), 5.67\left(\mathrm{t}, J=10.0 \mathrm{~Hz}, 1 \mathrm{H}, \mathrm{H}-3^{\prime \prime}\right), 5.42(\mathrm{dd}, J=17.2 \mathrm{~Hz}$, $\left.J^{\prime}=1.6 \mathrm{~Hz}, \quad 1 \mathrm{H}, \quad-\mathrm{CH}_{2} \mathrm{CH}=\mathrm{CH}_{2}\right), 5.28\left(\mathrm{~d}, J=1.6 \mathrm{~Hz}, \mathrm{H}-1^{\prime \prime}\right), 5.27(\mathrm{dd}$ $\left.J=9.2 \mathrm{~Hz}, J^{\prime}=1.2 \mathrm{~Hz}, 1 \mathrm{H},-\mathrm{CH}_{2} \mathrm{CH}=\mathrm{CH}_{2}\right), 5.11\left(\mathrm{~d}, J=4.0 \mathrm{~Hz}, 1 \mathrm{H}, \mathrm{H}-1^{\prime}\right)$, $4.37\left(\mathrm{dd}, J=9.6 \mathrm{~Hz}, J^{\prime}=6.4 \mathrm{~Hz}, 1 \mathrm{H}, \mathrm{H}-5^{\prime \prime}\right), 4.32\left(\mathrm{dd}, J=10.0 \mathrm{~Hz}, J^{\prime}=4.0 \mathrm{~Hz}\right.$ $\left.1 \mathrm{H},-\mathrm{CH}_{2} \mathrm{CH}=\mathrm{CH}_{2}\right), 4.27\left(\mathrm{~d}, J=4.8 \mathrm{~Hz}, 1 \mathrm{H}, \mathrm{H}-4^{\prime}\right), 4.01-3.97(\mathrm{~m}, 3 \mathrm{H}, \mathrm{H}-$ $2^{\prime},-\mathrm{CH}_{2} \mathrm{CH}=\mathrm{CH}_{2}$ and $\left.\mathrm{H}-3^{\prime}\right), 3.92\left(\mathrm{~d}, J=12.0 \mathrm{~Hz}, 1 \mathrm{H}, \mathrm{H}-5_{\mathrm{a}}{ }^{\prime}\right), 3.74(\mathrm{dd}$, $\left.J=13.2 \mathrm{~Hz}, J^{\prime}=1.6 \mathrm{~Hz}, 1 \mathrm{H}, \mathrm{H}-5_{\mathrm{b}}{ }^{\prime}\right), 1.34$ (d, $\left.J=6.0 \mathrm{~Hz}, 1 \mathrm{H}, \mathrm{H}-6^{\prime \prime}\right)$; ESI-MS: $m / z=714[\mathrm{M}+\mathrm{Na}]^{+}$; HR-FAB-MS: $m / z=713.6799[\mathrm{M}+\mathrm{Na}]^{+}$(Calcd for $\left.\mathrm{C}_{37} \mathrm{H}_{38} \mathrm{O}_{13} \mathrm{Na}, 713.6796\right)$

Allyl-2,3,4-tri- $O$-benzoyl- $\alpha$-L-rhamnopyranosyl-(1 $\rightarrow 2)$-3- $O$-benzoyl$\boldsymbol{\beta}$-L-arabinopyranoside (20) To a solution of $\mathbf{1 8}(240 \mathrm{mg}, 0.35 \mathrm{mmol})$ in dry pyridine $(10 \mathrm{ml}), \mathrm{BzCl}(122 \mu \mathrm{l}, 1.05 \mathrm{mmol})$ was added slowly at $0{ }^{\circ} \mathrm{C}$. After addition complete, the reaction mixture was warmed up to room temperature and stirred for overnight. Water $(0.40 \mathrm{ml})$ was added slowly to quench the reaction and the solvent was removed in vacuo. The resulting residue was dissolved in $\mathrm{CH}_{2} \mathrm{Cl}_{2}(50 \mathrm{ml})$, washed with water $(50 \mathrm{ml} \times 3)$, and then dried over $\mathrm{Na}_{2} \mathrm{SO}_{4}$ to afford crude compound 19 as a white amorphous solid, which was then dissolved in dry $\mathrm{CH}_{2} \mathrm{Cl}_{2}-\mathrm{MeOH}(1: 2,15 \mathrm{ml})$. To the solution was added $\mathrm{AcCl}(300 \mu \mathrm{l})$ at $0{ }^{\circ} \mathrm{C}$, and the solution was allowed to warm to room temperature and stirred for $12 \mathrm{~h}$ when starting material was completely disappeared. $\mathrm{Et}_{3} \mathrm{~N}(1.20 \mathrm{ml})$ was added to neutralize the acid. The solution was then concentrated and purified with a $\mathrm{Si}$ column chromatography using the $1: 1 \mathrm{cHx}-\mathrm{EtOAc}$ as eluent to give $20(180 \mathrm{mg}, 68.3 \%$ ) as a colorless solid: $\mathrm{mp} 75-78^{\circ} \mathrm{C} ;[\alpha]_{\mathrm{D}}^{25} 0.4^{\circ}\left(c=1, \mathrm{CHCl}_{3}\right)$; IR $\left(\mathrm{cm}^{-1}\right.$, $\mathrm{KBr}) 3450$ (O-H stretch), 2920 ( $s p^{3}-\mathrm{H}$ stretch), 1740 (conj. $\mathrm{C}=\mathrm{O}$ stretch), $1600(\mathrm{C}=\mathrm{C}$ stretch), 1520 and 1460 (aromatic $\mathrm{C}=\mathrm{C}$ stretch), 1260 and 1100 (C-O stretch); ${ }^{1} \mathrm{H}-\mathrm{NMR}\left(400 \mathrm{MHz}, \mathrm{CDCl}_{3}\right) \delta 8.12-7.23(\mathrm{~m}, 20 \mathrm{H}, \mathrm{Ar}-\mathrm{H})$, 6.06-5.96 $\left(\mathrm{m}, 1 \mathrm{H},-\mathrm{CH}_{2} \mathrm{CH}=\mathrm{CH}_{2}\right), 5.87-5.82\left(\mathrm{~m}, 2 \mathrm{H}, \mathrm{H}-2^{\prime \prime}\right.$ and $\left.\mathrm{H}-4^{\prime \prime}\right)$,

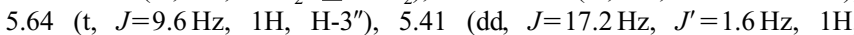
$\left.-\mathrm{CH}_{2} \mathrm{CH}=\mathrm{CH}_{2}\right), 5.25\left(\mathrm{~s}, 1 \mathrm{H}, \mathrm{H}-1^{\prime \prime}\right), 5.24\left(\mathrm{dd}, J^{\prime}=10.4 \mathrm{~Hz}, J^{\prime}=1.6 \mathrm{~Hz}, 1 \mathrm{H}\right.$, $\left.-\mathrm{CH}_{2} \mathrm{CH}=\mathrm{CH}_{2}\right), 5.12\left(\mathrm{~d}, J=3.6 \mathrm{~Hz}, 1 \mathrm{H}, \mathrm{H}-1^{\prime}\right), 4.44-4.36\left(\mathrm{~m}, 1 \mathrm{H}, \mathrm{H}-5^{\prime \prime}\right)$ $4.29\left(\mathrm{dd}, J=13.2 \mathrm{~Hz}, J^{\prime}=5.2 \mathrm{~Hz}, 1 \mathrm{H},-\mathrm{CH}_{2} \mathrm{CH}=\mathrm{CH}_{2}\right), 4.22(\mathrm{~d}, J=7.6 \mathrm{~Hz}$ $\left.1 \mathrm{H}, \mathrm{H}-4^{\prime}\right), 4.11\left(\mathrm{~s}, 1 \mathrm{H}, \mathrm{H}-2^{\prime}\right), 4.03\left(\mathrm{dd}, J=9.8 \mathrm{~Hz}, J^{\prime}=3.4 \mathrm{~Hz}, 1 \mathrm{H}, \mathrm{H}-3^{\prime}\right)$ $3.97\left(\mathrm{dd}, J=13.0 \mathrm{~Hz}, J^{\prime}=5.8 \mathrm{~Hz}, 1 \mathrm{H},-\mathrm{CH}_{2} \mathrm{CH}=\mathrm{CH}_{2}\right), 3.88(\mathrm{~d}, J=12.8 \mathrm{~Hz}$, $\left.1 \mathrm{H}, \mathrm{H}-5_{\mathrm{a}}{ }^{\prime}\right), 3.77$ (dd, $\left.J=12.4 \mathrm{~Hz}, J^{\prime}=1.6 \mathrm{~Hz}, 1 \mathrm{H}, \mathrm{H}-5_{\mathrm{b}}{ }^{\prime}\right), 1.33(\mathrm{~d}, J=6.4 \mathrm{~Hz}$ $\left.1 \mathrm{H}, \mathrm{H}-6^{\prime \prime}\right)$; ESI-MS: $m / z=776[\mathrm{M}+\mathrm{Na}]^{+}$; HR-FAB-MS: $m / z=775.7493$ $[\mathrm{M}+\mathrm{Na}]^{+}\left(\right.$Calcd for $\left.\mathrm{C}_{42} \mathrm{H}_{40} \mathrm{O}_{13} \mathrm{Na}, 775.7490\right)$.

Allyl-2,3,4-tri- $O$-benzoyl- $\alpha$-L-rhamnopyranosyl-( $1 \rightarrow 2)$-[2,3,4,6-tetra$O$-benzoyl- $\beta$-D-glucopyranosyl- $(1 \rightarrow 4)]$-3- $O$-benzoyl- $\beta$-L-arabinopyranoside (3) A suspension of $\mathbf{2 0}(90 \mathrm{mg}, 0.12 \mathrm{mmol})$, trichloroacetimidate $\mathbf{8}$ $(107 \mathrm{mg}, 0.14 \mathrm{mmol})$, and $4 \AA$ molecular sieves $(300 \mathrm{mg})$ in dry $\mathrm{CH}_{2} \mathrm{Cl}_{2}$ $(10 \mathrm{ml})$ was treated with TMSOTf $(2 \mu \mathrm{l}, 0.1 \mathrm{eq})$ in the same manner as that described for compound 9 . The product was purified by a Si gel column chromatography using the gradient solvent system $(c \mathrm{Hx}$-EtOAc, $3: 1 \rightarrow 1: 1)$ as eluent to give the desired compound $3(99 \mathrm{mg}, 62.0 \%)$ and is finally recrystallized as a colorless amorphous solid $(86 \mathrm{mg}, 52.9 \%)$ from petroleum ether-MeOH (3:1): $\mathrm{mp} 94-97^{\circ} \mathrm{C} ;[\alpha]_{\mathrm{D}}^{25} 0.9^{\circ}\left(c=1, \mathrm{CHCl}_{3}\right) ; \mathrm{IR}\left(\mathrm{cm}^{-1}\right.$, $\mathrm{KBr}) 2920\left(s p^{3}-\mathrm{H}\right.$ stretch), 1730 (conj. $\mathrm{C}=\mathrm{O}$ stretch), $1600(\mathrm{C}=\mathrm{C}$ stretch), 1450 (aromatic $\mathrm{C}=\mathrm{C}$ stretch), 1260 and $1110\left(\mathrm{C}-\mathrm{O}\right.$ stretch); ${ }^{1} \mathrm{H}-\mathrm{NMR}$ $\left(400 \mathrm{MHz}, \mathrm{CDCl}_{3}\right) \delta 8.09-6.94(\mathrm{~m}, 40 \mathrm{H}, \mathrm{Ar}-\mathrm{H}), 6.02-5.95(\mathrm{~m}, 1 \mathrm{H}$ $\left.-\mathrm{CH}_{2} \mathrm{CH}=\mathrm{CH}_{2}\right), 5.83-5.76\left(\mathrm{~m}, 2 \mathrm{H}, \mathrm{H}-3^{\prime \prime \prime}\right.$ and $\left.\mathrm{H}-2^{\prime \prime}\right), 5.69-5.58(\mathrm{~m}, 4 \mathrm{H}$, $\mathrm{H}-4^{\prime \prime \prime}, \mathrm{H}-4^{\prime \prime}, \mathrm{H}-3^{\prime \prime}$, and $\left.\mathrm{H}-2^{\prime \prime \prime}\right), 5.37\left(\mathrm{~d}, J=17.2 \mathrm{~Hz},-\mathrm{CH}_{2} \mathrm{CH}=\mathrm{CH}_{2}\right), 5.24(\mathrm{~s}$, $\left.1 \mathrm{H}, \mathrm{H}-1^{\prime \prime}\right), 5.21\left(\mathrm{~d}, J=10.8 \mathrm{~Hz}, 1 \mathrm{H},-\mathrm{CH}_{2} \mathrm{CH}=\mathrm{CH}_{2}\right), 5.02(\mathrm{~d}, J=3.6 \mathrm{~Hz}, 1 \mathrm{H}$, H-1'), 4.88 (s, $\left.1 \mathrm{H}, \mathrm{H}-1^{\prime \prime \prime}\right), 4.75$ (dd, $\left.J=14.0 \mathrm{~Hz}, J^{\prime}=5.2 \mathrm{~Hz}, 1 \mathrm{H}, \mathrm{H}-4^{\prime \prime \prime}\right), 4.55$ (d, $\left.J=9.2 \mathrm{~Hz}, 2 \mathrm{H}, \mathrm{H}-6^{\prime \prime \prime}\right), 4.42-4.36\left(\mathrm{~m}, 2 \mathrm{H}, \mathrm{H}-5^{\prime \prime \prime}\right.$ and $\left.\mathrm{H}-5^{\prime \prime}\right), 4.25(\mathrm{dd}$ $\left.J=13.2 \mathrm{~Hz}, J^{\prime}=5.2 \mathrm{~Hz}, 1 \mathrm{H},-\underline{\mathrm{CH}}_{2} \mathrm{CH}=\mathrm{CH}_{2}\right), 4.08\left(\mathrm{~s}, 1 \mathrm{H}, \mathrm{H}-2^{\prime}\right), 3.98(\mathrm{dd}$ $\left.J=9.2 \mathrm{~Hz}, J^{\prime}=3.6 \mathrm{~Hz}, 1 \mathrm{H}, \mathrm{H}-3^{\prime}\right), 3.92\left(\mathrm{dd}, J=12.8 \mathrm{~Hz}, J^{\prime}=6.0 \mathrm{~Hz}, 1 \mathrm{H}\right.$, $\left.-\mathrm{CH}_{2} \mathrm{CH}=\mathrm{CH}_{2}\right), 3.78\left(\mathrm{~d}, J=12.4 \mathrm{~Hz}, 1 \mathrm{H}, \mathrm{H}-5_{\mathrm{a}}{ }^{\prime}\right), 3.68(\mathrm{~d}, J=12.4 \mathrm{~Hz}, 1 \mathrm{H}$, H- $\left.{ }_{\mathrm{b}}{ }^{\prime}\right), 1.32$ (d, $\left.J=6.4 \mathrm{~Hz}, 1 \mathrm{H}, \mathrm{H}-6^{\prime \prime}\right)$; ESI-MS: $m / z=1354\left[\mathrm{M}+\mathrm{Na}^{+}\right.$; HRFAB-MS: $m / z=1354.3129[\mathrm{M}+\mathrm{Na}]^{+}\left(\right.$Calcd for $\mathrm{C}_{76} \mathrm{H}_{66} \mathrm{O}_{22} \mathrm{Na}, 1354.3138$ ).

Cell Culture Assay The cytotoxicity assay was carried out according to the SRB assay described previously. ${ }^{27)}$ Three human cancer cell lines, A-549 (Lung cancer), SK-OV-3 (Ovarian cancer) and SK-MEL-2 (Skin cancer) were examined, and doxorubicin was used as the positive control $\left(\mathrm{ED}_{50}\right.$ : $0.02,0.1,0.04 \mu \mathrm{M}$, respectively). Growth inhibition of $50 \%\left(\mathrm{ED}_{50}\right)$ of $3 \mathrm{cal}-$ culated using the method described elsewhere. ${ }^{28)}$ Briefly, the cells were divided into 96-well plates and preincubated on the plates for $24 \mathrm{~h}$. The compounds were added to the wells and incubated for $48 \mathrm{~h}$. After incubation, the culture medium in each well was removed, and the cells were fixed with cold $10 \%$ trichloroacetic acid. Subsequently, a $0.4 \%$ SRB solution in $1 \%$ acetic acid was added to each well. The optical density was measured in a microtiter plate reader at $540 \mathrm{~nm}$.

\section{References}

1) Hostettmann K., Marston A., "Chemistry and Pharmacology of Natural Products; Saponins," Cambridge University Press, London, 1995, p. 18

2) Shaojiang D., Biao Y., Jianming X., Yongzheng H., J. Org. Chem., 64 7265-7266 (1999)

3) Nakamura T., Komori C., Lee Y., Hashimoto F., Yahara S., Nohara T., Ejima A., Biol. Pharm. Bull., 19, 564-566 (1996).

4) Arao T., Udayama M., Kino J., Nohara T., Funakoshi T., Kojima S. Biol. Pharm. Bull., 20, 988 -991 (1997).

5) Kim Y., Bang S. C., Lee J. H., Ahn B. Z., Arch. Pharm. Res., 27, 915-918 (2004)

6) Bang S. C., Kim Y., Lee J. H., Ahn B. Z., J. Nat. Prod., 68, 268-272 (2005).

7) Bang S. C., Lee J. H., Song G. Y., Kim D. H., Yoon M. Y., Ahn B. Z., Chem. Pharm. Bull., 53, 1451-1454 (2005).

8) Park H. J., Kwon S. H., Lee J. H., Lee K. H., Miyamoto K., Lee K. T., Planta Med., 67, 118-121 (2001).

9) Mimaki Y., Kuroda M., Asano T., Sashida Y., J. Nat. Prod., 62, 12791283 (1999).

10) Brown R. S., Wahl R. I., Cancer, 72, 2979-2983 (1993).

11) Yamamoto I., Sekine M., Hata T., J. Chem. Soc. Perkin 1, 1980, 306 310 (1980).

12) Polt R., Porreca F., Szabo L. Z., Bilsky E. J., Davis P., Abbruscato T. J., Davis T. P., Horvath R., Yamamura H. I., Hruby V. J., Proc. Natl. Acad. Sci. U.S.A., 91, 7114-7118 (1994).

13) Halmos T., Santarromana M., Antonakis K., Scherman D., Eur. J. Pharmacol., 318, 477-484 (1996).

14) Uriel C., Egron M. J., Santarromana M., Scherman D., Antonakis K., Herscovici J., Bioorg. Med. Chem., 4, 2081-2090 (1996).

15) James K. T., Wang S. P., Mary B. T., Shawn B., Daniel J. R., Dexter L. M., David S. W., Donald C. L., Proc. Natl. Acad. Sci. U.S.A., 103, 10461-10466 (2006).

16) Maoquan Z., George A. O’Doherty, J. Org. Chem., 72, 2485-2493 (2007).

17) Xiangdong M., Linsen H., Mingkun F., Zhimin L., Jun N., Carbohydr Res., 340, 2345-2351 (2005).

18) Schmidt R. R., J. Angew. Chem. Int. Ed., 19, 731-732 (1980).

19) Karen P., Martin C., Laurence V. N., Eur. J. Org. Chem., 2004, 15881603 (2004).

20) Kartha K. P. R., Field R. A., J. Carbohydr. Chem., 17, 693-702 (1998).

21) Balaram M., Robert A. F., Carbohydr. Res., 339, 1285-1291 (2004)

22) Shyam M. R., Suri S. I., Subramanian B., Elliot L. C., J. Org. Chem., 
69, 9159-9170 (2004).

23) Biao Y., Jianming X., Shaojiang D., Yongzheng H., J. Am. Chem. Soc., 121, 12196-12197 (1999)

24) Paul F., George M. I., Aloysius H. S., Carbohydr. Res., 210, 319-325 (1991).

25) Ziegler T., Bien F., Jurisch C., Tetrahedron: Asymmetry, 9, 765-780 (1998).

26) Shayne C. G., "Drug Discovery Handbook," John Wiley \& Sons Press,
New York, 2005, pp. 739-740.

27) Skehan P., Storeng R., Scudiero D., Monks A., McMahon J., Vistica D., Warren J. T., Bokesh H., Kenney S., Boyd M. R., J. Natl. Cancer Inst., 82, 1107-1112 (1990).

28) Monks A., Scudiero D., Skehan P., Shoemaker R., Paull K., Vistica D., Hose C., Langley J., Cronise P., Vaigro W. A., Gray G. M., Campbell H., Mayo J., Boyd M., J. Natl. Cancer Inst., 83, 757-766 (1991). 